\title{
LOS PELIGROS DE LA GENÉTICA: INVESTIGACIÓN CIENTÍFICA, PERIODISMO DE CIENCIA Y CONFLICTO INTERDISCIPLINAR A LA LUZ DE UNA RECIENTE POLÉMICA SOBRE ARQUEOLOGÍA EN ESPAÑa Y PORTUGAL
}

\author{
DANGERS OF GENETICS: SCIENTIFIC RESEARCH, SCIENCE JOURNALISM, AND \\ INTERDISCIPLINARY CONFLICT, WITH REGARD TO A RECENT ARCHAEOLOGICAL \\ CONTROVERSY IN SPAIN AND PORTUGAL
}

\author{
MARTÍN FERNÁNDEZ CALO \\ martin.fernandez.calo@rai.usc.es \\ Universidade de Santiago de Compostela (España)
}

RECIBIDO: $24 / 04 / 2019$
ACEPTADO: $21 / 06 / 2019$

Resumen: Un manifiesto de destacados especialistas en Arqueología y otras materias ha sido dirigido recientemente contra un periódico por su tratamiento de una noticia sobre arqueogenética, enrareciendo la relación entre investigación científica y periodismo de ciencia en España y Portugal. Atendiendo a las últimas publicaciones periodísticas y científicas sobre este campo, se argumenta que el manifiesto es infundado y que las vías de investigación planteadas por los genetistas deberían comenzar a ser seriamente exploradas por arqueólogos e historiadores.

Palabras clave: arqueología, arqueogenética, conflicto interdisciplinar, periodismo de ciencia, Prehistoria de la península ibérica.

\begin{abstract}
Recently, prominent specialists in Archaeology and other fields wrote a manifesto against a newspaper because of its covering of a news about archaeogenetics, clouding the relationship between scientific research and science journalism in Spain and Portugal. Attending the latest journalistic and scientific publications on this field, this article shows the aforesaid manifesto is baseless, and that the research pathways proposed by geneticists should start to be seriously explored by historians and archaeologists.
\end{abstract}

Keywords: archaeology, archaeogenetics, interdisciplinary conflict, science journalism, Prehistoric Iberia.

\section{Un artículo incómodo}

"Porque puede ser peligroso". Esa fue la razón que un profesor de la Universidad de Santiago de Compostela, en un - por otra parte, acertado e incluso inspirador - seminario sobre cultura indoeuropea que él mismo coordinaba, esgrimió para reprender una tímida alusión mía a los avances que los estudios genéticos están produciendo en el conocimiento de la Prehistoria europea. Mi intervención no fue discutida en base a su inexactitud, sino a sus potencialmente indeseables implicaciones sociales. Semejante actitud puede parecer exagerada, 
pero no carece de justificación: la integración de los datos genéticos con los arqueológicos significa, como mínimo, rozar los límites entre cultura y biología; y no es preciso insistir en por qué esto puede generar inquietud. Y lo cierto es que aquel día, hace un par de años, nada más pronunciar yo "genética", esa palabra fatal, pude olerme - e inmediatamente oír - la misma desaprobación entre algunos de mis compañeros, doctorandos en Historia, Historia del Arte y Arqueología.

Si una insignificante intervención como la mía - la de un lego en arqueogenética en un seminario formativo - puede incomodar a profesores universitarios e incluso a historiadores y arqueólogos en formación, a menudo más abiertos a las novedades científicas, no resultará extraña la reacción que en octubre de 2018 provocó en el establishment académico hispano-portugués un artículo de Manuel Ansede para el diario español El País sobre este mismo tema, titulado "una invasión borró del mapa a los hombres de la península ibérica hace 4.500 años" (Ansede, 2018). El artículo se hacía eco de una entonces reciente conferencia del genetista David Reich en el evento New Scientist Live, en Londres, donde éste habría expresado una particular visión de la Prehistoria de la península ibérica a la luz de sus investigaciones sobre ADN antiguo. Según la síntesis de Manuel Ansede, por sólo citar sus pasajes más criticados, David Reich habría defendido que en el III milenio a.C. poblaciones procedentes de la estepa eurasiática "llegaron a la península ibérica", "conquistaron el territorio", "borraron del mapa a los varones locales" y "tuvieron un acceso preferente a las mujeres"... Un auténtico veni vidi vici de la Edad del Bronce.

El artículo de Manuel Ansede fue publicado el día 2 de octubre en la web de El País y el día 3 en papel; y ya el día 5 se difundía en Internet un manifiesto para recusarlo (Valera et al., 2018). Ello no tendría mayor relevancia de no ser por la suscripción del mismo por casi un centenar de especialistas en Arqueología y otras materias, la mayoría miembros de universidades y centros de investigación de España y Portugal. El manifiesto tomó forma de carta, dirigida "a El País y a otros medios"; pero su publicación en redes sociales por los propios firmantes y su inmediata difusión la convirtieron en una carta abierta. En resumen, su denuncia giró en torno a tres ejes, que ampliaremos en su momento, pero que me limitaré ahora a enunciar:

a) manipulación periodística;

b) insensibilidad social;

c) inexactitud científica.

Todo ello - de notoria gravedad, de ser cierto- exigiría pues una satisfacción del medio responsable: 
Solicitamos [...] que El País publique nuestra declaración y rectifique respecto a la noticia dada, que es esencialmente incorrecta desde un punto de vista científico estricto y que confunde gravemente al público sobre la realidad científica de nuestra Prehistoria (Valera et al., 2018).

Aunque la carta misma tuvo una buena acogida no sólo en redes sociales sino también en los medios digitales, donde llegó a encabezar la sección de ciencia de algún periódico (por ejemplo, Martínez Ron, 2018), El País se hizo eco de la misma para poco más que justificar a su periodista (Galán, 2018). Se ha producido así una insólita ruptura entre dos ámbitos sociales, la investigación científica y el periodismo de ciencia, que por definición debieran ir de la mano; pero las causas de este hecho son mucho más profundas que la simple polémica entre quienes hacen ciencia y los que informan sobre ella. En efecto, no estamos meramente ante la simplificación y/o tergiversación periodística de unos resultados científicos, sino ante la propia discrepancia disciplinar, fundamentalmente entre arqueólogos y genetistas, sobre qué hacer con - y cómo interpretar - tales resultados... Un problema, en suma, de rabiosa actualidad y que comienza a suscitar un notable interés social y científico (Callaway, 2018).

Es por ello que el presente artículo propone profundizar sobre este asunto, tratando de mantener una actitud equidistante entre las posturas en conflicto, pese a enfocarse - huelga ocultarlo - desde la óptica de las ciencias humanas. Ciertamente, el diálogo interdisciplinar ha de realizarse a partir de aportaciones de cada disciplina; pero tales aportaciones deben ser flexibles, no dogmáticas, y no pueden por tanto limitarse a la defensa acrítica de los principios de la disciplina propia. Exploraremos así uno por uno la validez de los tres ejes de denuncia que acabamos de identificar, pero al probar su inconsistencia pasaremos a reflexionar sobre el enfoque que desde la Arqueología se ha venido manteniendo por lo común hacia los descubrimientos de la arqueogenética.

\section{La creación de una noticia}

El primer eje de denuncia del que nos hemos hecho eco es la manipulación periodística, sugerida ya en el ingenioso título del manifesto, "genética de una fake news", y mantenida a lo largo del mismo:

La noticia en cuestión es preocupante por la falta de rigor, por la simplificación, por la superficialidad, por la sumisión a la búsqueda de la espectacularidad y, en definitiva, por la irresponsabilidad. [...] Se basa [...] en una composición de 
declaraciones descontextualizadas y luego re-armadas en forma de una noticia exagerada, infundada y carente de rigor.

Sin embargo, ninguna de estas acusaciones surge de análisis alguno del origen de la noticia. La genética de la supuesta fake news nos lleva de hecho a la semana y mes anteriores, al 28 de septiembre, cuando la web de New Scientist se hizo eco de la conferencia de David Reich, desarrollada el día 22. El título de esta noticia matriz tal vez no sorprenda ahora, pues es prácticamente el mismo, aunque en inglés, que el escogido por Manuel Ansede. Lo traducimos: "todos los hombres de España fueron aniquilados por invasores hostiles hace 4.500 años" (Marshall, 2018). Sorprendentemente, el manifiesto no hizo extensible a dicha revista, fuente de la noticia, la denuncia y exigencia de rectificación dirigidas contra $\mathrm{El}$ País; y eximió de toda responsabilidad al genetista implicado, David Reich, aun cuando el artículo de Manuel Ansede, que se limitó en este aspecto a traducir el anterior de New Scientist, le atribuía textualmente alguna de las expresiones "tuvieron un acceso preferente a las mujeres locales"; "desplazaron a los hombres locales casi por completo" - más duramente criticadas. David Reich debería haber sido el principal interesado en pedir explicaciones a El País en caso de una manipulación tan grave de sus palabras como la sugerida en el manifiesto; pero paradójicamente éste se realizó a sus espaldas, desconociendo los firmantes su opinión personal al respecto:

Somos conscientes de la prudencia y rigor con que los responsables de este estudio - recordemos, aún no publicado - tratan sus investigaciones. Y por ello nos sorprendería mucho que la manera y el lenguaje con que las mismas han sido presentadas en El País contasen con su aval (Valera et al., 2018).

Los firmantes pueden entonces sorprenderse, pues el autor del artículo denunciado, según testimonio de una colega, Lola Galán, se preocupó expresamente por obtener dicho aval:

Manuel Ansede, colaborador de la sección de ciencia y autor del artículo, explica que, antes de sentarse ante el ordenador, contactó con los autores del estudio. "Ninguno de ellos desmintió lo publicado por New Scientist —es más, uno de ellos confirmó la veracidad del artículo-, pero los tres declinaron ofrecer más detalles públicamente". [...] Ansede me explica que escribió también a los investigadores Rui Martiniano, del Wellcome Sanger Institute, y Daniel Bradley, del Trinity College de Dublín, autores de un trabajo previo sobre la genética de la Edad del Bronce en la península ibérica. Ambos encontraron plausible lo publicado por New Scientist (Galán, 2018). 
Este testimonio tira por tierra toda la premisa central del manifiesto: que Manuel Ansede, carente de "rigor científico y periodístico", hubiera tergiversado las palabras de David Reich. Parece, por el contrario, que el genetista habría avalado nada menos que el tratamiento de la noticia de New Scientist, que fue esencialmente el mismo, como hemos visto, que el de El País. Por supuesto, las implicaciones del testimonio de Lola Galán sobre la praxis de su compañero dependen de la confianza que depositemos en ella; pero lo que sí sabemos es que la misma institución que acogió la conferencia de David Reich, New Scientist, fue la que publicó la noticia con todas sus supuestas exageraciones, y que aquél, aun habiendo sido consultado, no las desdijo. Como mínimo, estamos ante un aval por omisión, que no dejaría de ser un aval, al fin y al cabo.

La producción científica de David Reich, a menudo de autoría múltiple y fines esencialmente técnicos, no permite acercarse a sus opiniones personales sobre la Prehistoria. De hecho, el estudio en el que se basó su conferencia para el New Scientist Live, publicado seis meses después de la polémica que nos ocupa, se limitó a sentenciar, tras sintetizar sus resultados, que "se necesita investigación arqueológica y antropológica para comprender[los]" (Olalde et al., 2019, p. 1231). Sin embargo, en su obra divulgativa nuestro genetista no se muestra tan comedido. Son los capítulos sobre Europa e India de su reciente y ya controvertido libro, Who we are and how we got here, los de mayor interés para dilucidar esta cuestión (Reich, 2018a, pp. 99-153); aunque por ahora prefiero aislar el siguiente texto, tomado de un artículo divulgativo, por condensar de un modo más sintético el mismo contenido:

El ADN antiguo ha evidenciado que [la cultura calcolítica de la estepa eurasiática] Yamna fue en efecto una sociedad donde el poder estaba concentrado en una pequeña élite de varones. [...] Sus descendientes [...] difundieron su cromosoma Y por Europa e India; y el impacto demográfico de esta expansión fue profundo, pues sus variantes del cromosoma, siendo predominantes hoy, [...] habían estado ausentes antes de la Edad del Bronce. Esta expansión yamnaya tampoco pudo ser completamente amistosa. [...] La preponderancia [actual] de ascendencia masculina originada en la estepa implica que los varones descendientes de los yamnaya con poder socio-político fueron más exitosos que los autóctonos en la competencia por encontrar pareja. El caso más sorprendente que conozco es el de Iberia, [...] donde la ascendencia relacionada con Yamna irrumpió al comienzo de la Edad del Bronce, hace entre 4.500 y 4.000 años. [...] Hemos descubierto que en los primeros ibéricos con ascendencia genética relacionada con Yamna, su proporción era de menos del 15\% en todo el genoma. Sin embargo, alrededor del $90 \%$ de los varones con tal ascendencia tenían una variante del cromosoma Y procedente de la estepa, que había estado ausente de 
Iberia hasta entonces. Claro está que hubo extraordinarias jerarquías y desigualdades [...] detrás de ello (Reich, 2018b).

A lo que podemos añadir otro par de fragmentos, ahora ya sí del libro. He aquí el primero:

El ADN antiguo [...] puede demostrar los movimientos de pueblos del pasado, y [en la cultura calcolítica noreuropea de la cerámica cordada] ha documentado un reemplazamiento demográfico de tal magnitud que ningún arqueólogo moderno, incluso el más ferviente migracionista, se había atrevido a proponer (Reich, 2018a, p. 112).

Y el segundo:

El registro genético muestra que los yamnaya y sus descendientes fueron extraordinariamente exitosos, desplazando ampliamente a los agricultores de Europa septentrional en el oeste y a los cazadores-recolectores de Asia central en el este (Reich, 2018a, p. 237).

Ciertamente, no hace falta haber asistido al New Scientist Live o tratar personalmente a David Reich para percatarse de que es muy probable que en su conferencia se hubiera expresado de un modo muy similar al que plasmó Manuel Ansede en su vituperado artículo. De hecho, los propios textos seleccionados arriba, meses anteriores al evento en cuestión, contienen base para cada una de las presuntas tergiversaciones del periodista; aunque justo es reconocer que con diferentes grados de afinidad. Que cada cual juzgue según su criterio (véase Tabla 1).

\begin{tabular}{|c|c|}
\hline DAVID REICH & MANUEL ANSEDE \\
\hline $\begin{array}{l}\text { "Yamnaya-derived ancestry arrived } \\
\text { suddenly at the onset of the Bronze } \\
\text { Age between } 4,500 \text { and } 4,000 \text { years } \\
\text { ago". }\end{array}$ & \multirow[t]{2}{*}{$\begin{array}{l}\text { "Hace } 4.500 \text { años descendientes de estos } \\
\text { habitantes de las estepas llegaron a la } \\
\text { península Ibérica". }\end{array}$} \\
\hline \multirow{2}{*}{$\begin{array}{l}\text { "Ancient DNA can prove past } \\
\text { movements of people that no modern } \\
\text { archaeologist, even the most ardent } \\
\text { supporter of migrations, had dared to } \\
\text { propose". }\end{array}$} & \\
\hline & \multirow[t]{2}{*}{ "Los yamnayas conquistaron el territorio". } \\
\hline $\begin{array}{l}\text { "This Yamnaya exp } \\
\text { cannot have been er }\end{array}$ & \\
\hline
\end{tabular}




\begin{tabular}{|l|l|}
\hline $\begin{array}{l}\text { "Yamnaya and their descendants } \\
\text { were extraordinarily successful, } \\
\text { largely displacing the farmers of } \\
\text { northern Europe". }\end{array}$ & $\begin{array}{l}\text { "Descendientes de estos habitantes de } \\
\text { la estepa [...] borraron del mapa a los } \\
\text { varones locales". }\end{array}$ \\
\hline $\begin{array}{l}\text { "Male descendants of the Yamnaya } \\
\text { with political or social power were } \\
\text { more successful at competing for } \\
\text { local mates". }\end{array}$ & $\begin{array}{l}\text { "Los hombres que llegaron tuvieron } \\
\text { un acceso preferente a las mujeres } \\
\text { locales". }\end{array}$ \\
\hline
\end{tabular}

TABLA 1. Comparativa entre afirmaciones de David Reich (2018a y b) y Manuel Ansede (2018)

En cualquier caso, es evidente que el manifiesto que nos ocupa no ha calculado bien las responsabilidades detrás del artículo denunciado. Las expresiones más criticadas del mismo derivan de un artículo anterior de New Scientist con idénticas citas textuales a las declaraciones de David Reich, y el fondo de todas y cada una de sus sugerencias supuestamente contrarias a "realidad científica de nuestra Prehistoria" puede encontrarse sin dificultad en la obra divulgativa del citado genetista. Éste no desdijo a los medios que se hicieron eco de su conferencia, e incluso, según declaración de Lola Galán, él o su equipo los habrían avalado expresamente. Es claro que David Reich, en toda la difusión de estas informaciones pretendidamente escandalosas, alguna responsabilidad tuvo. Manuel Ansede se limitó a hacerse eco de la noticia de New Scientist y a enriquecerla con información adicional tomada de la consulta de otros investigadores; al parecer sin olvidarse de verificar su información a partir de fuentes cruzadas, realizando en este sentido $-\mathrm{y}$ al margen de su titular sensacionalista - una impecable labor periodística. El País fue mero receptáculo, por mucho que una vez estallada la polémica tomase partido por su profesional. El manifiesto debería haberse dirigido si acaso contra David Reich y New Scientist, y no - como ha sido - contra Manuel Ansede y El País.

Advertimos un mayor sesgo, por tanto, en el manifiesto que en el artículo: éste, correcto o no a nivel científico, fue confrontado con las opiniones de varios investigadores; aquél se limitó a achacar toda una batería de supuestas inexactitudes, unidireccionalmente y sin razón alguna, a la mala praxis periodística. Quizá los firmantes no habrían cometido semejante exceso si realmente hubieran profundizado en la "genética" de la noticia, como venimos de hacer en estas páginas. De hecho, el propio David Reich ha hecho pública en su obra divulgativa (Reich, 2018a, p. 112) y ante los medios (Callaway, 2018; Rincon, 2018) su decepción con el escepticismo y eventual oposición que los 
arqueólogos suelen mostrar hacia sus trabajos; e incluso ha sido ya objeto de otra carta abierta contra su manera de enfocar el estudio de un tema tan sensible socialmente como el del trasfondo genético de las razas humanas (Kahn et al., 2018). Ciertamente, no parece muy probable que los cerca de cien firmantes del manifiesto que nos ocupa estuvieran al tanto, cada uno de ellos, de la trayectoria personal de David Reich; pero aun de ser así, habiendo esta otra carta abierta de por medio contra él, demostraron no ser "conscientes de [su] prudencia y rigor", puesta en duda por otros académicos, sino que simplemente la dieron por hecho. Se limitaron así a exculparlo de toda responsabilidad en los supuestos desaciertos contenidos en el artículo de El País, achacándoselos a Manuel Ansede; como si un científico, con independencia de su trayectoria, no pudiera cometer errores, o un periodista, a pesar de su formación científica, fuera por naturaleza más proclive a hacerlo. Este acto de matar al mensajero y evitar toda confrontación con un colega de gran influencia mediática y científica podría achacarse a la simple cobardía de los firmantes; pero esto sería probablemente injusto, pues todo apunta a que es otro sesgo por su parte el que está realmente operando aquí. La clave nos la proporciona la sugerencia de que el público habría sido "gravemente" confundido por la noticia, como si un lector medio no pudiera juzgarla o simplemente ignorarla de acuerdo con su propio criterio: el sesgo en cuestión no es otro que una considerable suficiencia académica hacia los periodistas y el público en general.

\section{¿Por qué ahora?}

Ya hemos apuntado que los firmantes del manifiesto no sólo justificaron su reacción en el pretendido amarillismo periodístico del artículo denunciado, sino también en su insensibilidad social, que compone el segundo eje de denuncia. En su manifiesto se acarició, de hecho, la misma advertencia contra los «peligros de la genética» a la que aludimos al comienzo de este artículo:

En vista de las actuales circunstancias históricas relativas a los fenómenos migratorios, [...] este campo de investigación del Pasado no podría ser más oportuno, demostrando la relevancia social de las ciencias históricas en general, y de la arqueología en particular, para contribuir efectivamente a la comprensión y resolución de los problemas presentes. Pero precisamente por ello [...] la responsabilidad es muy grande, y desde luego incompatible con la ligereza que se presta a una manipulación fácil e impúdica. La actual sensibilidad social y política con respecto a los procesos migratorios, o simplemente con respecto al «extranjero», exigen responsabilidad, rigor y compromiso ético-profesional tanto 
de parte de quienes investigan sobre estas temáticas como de quienes informan de ello al gran público (Valera et al., 2018).

Sobre los principios éticos contenidos en este párrafo no cabría objeción alguna, de no ser porque van precisamente dirigidos contra la supuesta violación de los mismos por parte de Manuel Ansede - por supuesto, nunca contra David Reich-, lo cual es muy discutible. Contra la advertencia del manifiesto, en efecto, una noticia sobre migraciones prehistóricas supuestamente destructivas no tiene por qué suponer ninguna falta de respeto "al extranjero" ni atentar contra la "actual sensibilidad social y política" hacia la inmigración; especialmente si esa noticia informa también, como es el caso, de que la actual población desciende de aquellos hipotéticos migrantes prehistóricos. Sin embargo, cualquier reflexión de este tipo quizá incurra en un exceso de suspicacia: puede parecer ridículo señalarlo, pero para el gran público, simplemente, la Prehistoria suena mucho más lejana que para los expertos en Arqueología.

Mas aun suponiendo que ante el titular de El País sólo cupiera una lectura negativa, ¿es la comunidad académica o la sociedad en conjunto quien debe juzgar su grado de tolerabilidad? ¿Tiene o no el gran público derecho a ser informado de cualquier hipótesis científica, incluso si puede sonar «peligrosa» para determinadas sensibilidades ideológicas? Todas estas cuestiones son sin duda muy pertinentes, pero ni que decir tiene que no son sólo los académicos versados en una determinada disciplina quienes deben dilucidarlas. No entraré en los derechos que podrían considerarse conculcados en caso de ocultación deliberada de información científica por parte de entidades públicas (cfr. Pacto Internacional de Derechos Económicos, Sociales y Culturales, art. 15): baste con señalar que si la prensa juzgó socialmente inocuo un artículo como el de Manuel Ansede, el criterio de sus profesionales es a priori tan válido como el de los expertos en Arqueología.

Además, la influencia mediática de la investigación genética no es ni mucho menos un fenómeno reciente. La única novedad es la oposición de un sector académico contra su tratamiento informativo. Hace tan sólo una década, cuando apenas se conocían muestras de ADN antiguo, los genetistas tendían a atribuir hoy sabemos que erróneamente - el actual mapa genético de Europa a flujos y reflujos de poblaciones ya asentadas en el continente desde el Paleolítico (por ejemplo, Sykes, 2006; Oppenheimer, 2007). Significativamente, esta aparente base genética sirvió a la escuela del lingüista Mario Alinei, recientemente fallecido, para fundamentar su teoria della continuità, según la cual las lenguas indoeuropeas serían autóctonas de la Europa occidental paleolítica (para una 
síntesis, Alinei, 2008). Semejantes aportaciones, ajenas a los consensos vigentes tanto entonces como ahora en Arqueología, fueron a menudo ignoradas por el sector «ortodoxo» de la disciplina, sin discriminar que algunos estudios solventes se preocupasen por rebatirlas convenientemente (así, Calo Lourido, 2010, pp. 28 30 ). No obstante, tuvieron buena acogida en los medios, a través de titulares más o menos rocambolescos (por ejemplo, Conde, 2006; Azurmendi, 2011) que no generaron reacción pública alguna por parte del ámbito académico... Y ello, a pesar de que la idea de una Europa inalterada a nivel genético desde el Paleolítico, aparte de inverosímil, podría alimentar - y de hecho así ha sido (cfr. Demoule, 2017 [2014], pp. 389-392) — derivas tanto o más racistas que un titular sobre invasiones supuestamente ocurridas en la Edad del Bronce.

Los avances en arqueogenética han puesto en entredicho todas estas teorías, al evidenciarse primero algo aparentemente tan obvio como que el mapa genético actual de Europa difiere del de la Prehistoria (Levy-Coffman, 2005); y más tarde al acotarse dos grandes rupturas genéticas a lo largo de la misma: el Neolítico (por ejemplo, Hervella et al., 2012; Brotherthon et al., 2013) y la Edad del Bronce, proceso del que pronto nos ocuparemos. Es así como desde hace unos años noticias similares a la de Manuel Ansede han venido jalonando los titulares de ciencia de la prensa internacional. Por ejemplo, el suplemento dominical de la suiza Neue Zürcher Zeitung, reconocida no precisamente por su sensacionalismo, tituló: "Invasión desde el este: lo que unos migrantes nos trajeron hace milenios" (Franz, 2017). Y un periódico tan poco sospechoso de tomarse a la ligera los problemas sociales actuales como The Guardian opuso: "¿Exterminaron hordas holandesas a los antiguos británicos que construyeron Stonehenge?" (McKie, 2017)... Ciertamente, semejantes titulares no tienen nada que envidiar al de Manuel Ansede, y sin embargo no suscitaron la reacción de los académicos de sus países contra los medios implicados.

Por último, si comparamos el manifiesto que nos ocupa con un claro precedente nos sorprenderá que ambos pretendan justificarse indistintamente en el compromiso social de la Arqueología: me refiero a la declaración de la Asociación Europea de Arqueólogos contra el desarrollo y subvención pública de las intervenciones pseudocientíficas de Samir Osmanagić en las autoproclamadas «pirámides bosnias» (Parzinger et al., 2006). Son evidentes las implicaciones sociales de la Arqueología en este asunto: la defensa del patrimonio arqueológico y la demanda de políticas acertadas a su favor. No fueron las fantásticas pretensiones de Samir Osmanagić lo denunciado por esta declaración, pues recusar una hipótesis, por absurda que sea, no tiene nada que ver con el compromiso social, sino con la Ciencia. ¿Dónde está, por tanto, el compromiso social de la Arqueología en el manifiesto que nos ocupa? En ninguna parte lo 
encontramos: sólo entreveremos, si acaso, la sensibilidad ideológica de sus firmantes, tan legítima como cualquier otra, pero que nada tiene que ver con la Arqueología.

Lo que ha demostrado el establishment arqueológico hispano-portugués no es en definitiva su compromiso social: si así hubiera sido, el manifiesto podría haberse producido hace ya un par de años, cuando la prensa internacional comenzó a publicar noticias sobre supuestas invasiones prehistóricas, o hace diez, cuando lo que estaba de moda era la continuidad paleolítica. En realidad, el manifiesto que nos ocupa exhibe la menor tolerancia de sus firmantes, con respecto a sus colegas europeos, hacia perspectivas ajenas a los consensos por ellos mismos asumidos. Claramente esto no es compromiso social sino, si acaso, compromiso disciplinar: algo en sí mismo muy loable, pero que, usado para desdeñar los aportes de otras disciplinas por el simple inmovilismo de la propia, deviene en mero corporativismo. Ahora bien, antes de profundizar en este sesgo conviene que nos detengamos en las razones que han venido a discutir, desde otra disciplina, los principios comunes hoy por hoy vigentes en Arqueología.

\section{Lo que la Arqueogenética ha desentrañado}

Comencemos con una curiosidad: el genetista Rui Martiniano, firmante del manifiesto que nos ocupa, es también coautor del primer gran estudio arqueogenético sobre la Edad del Bronce ibérica, y el único publicado cuando estalló la polémica que nos ocupa (Martiniano et al., 2017). Este estudio, que por algún motivo no trascendió a los medios españoles, sí fue dado a conocer hace un par de años en un muy documentado y didáctico artículo de Teresa Firmino para el diario portugués Público, lo cual no pareció molestar a nadie en su momento, pese a que - y esto sí que es curioso - aludiera a "invasiones" en su propio título. De hecho, un año después, consultado por Manuel Ansede a propósito de la conferencia de David Reich, Rui Martiniano trató de explicar el supuesto éxito de las "poblaciones de las estepas" en la península ibérica por su "tecnología superior", sus "mejores armas y [...] caballos domesticados", que les conferirían "alguna ventaja en la guerra" (Ansede, 2018). Unos días después, y de un modo cuando menos paradójico, firmó el manifiesto contra la visión «invasionista» que Manuel Ansede plasmó finalmente en su artículo. Sin embargo, lo cierto es que en 2017, como en el manifiesto y al contrario que en sus declaraciones a Manuel Ansede y el propio titular escogido por Teresa Firmino, Rui Martiniano trataba efectivamente de matizar todo «invasionismo»: 
"En contraste con otras regiones europeas", refiere Rui Martiniano, [...] "sólo detectamos una mudanza genética muy sutil durante la transición del Neolítico a la Edad del Bronce, como resultado de migraciones o del contacto con otros pueblos de fuera de la península ibérica” (Firmino, 2017).

Según continuaba Teresa Firmino, el genetista defendería asimismo el efecto que este escaso influjo genético externo habría tenido en la mayor supervivencia de las lenguas no indoeuropeas en la península ibérica y la menor estatura media de su población frente a otras regiones del continente (Firmino, 2017). Tales correlaciones fueron efectivamente abordadas en el estudio en cuestión (cfr. Martiniano et al., 2017, pp. 10-13); pero el hecho de que Rui Martiniano decidiera priorizarlas sobre otros resultados muestra a las claras cómo incluso en una disciplina tan técnica como la genética unos mismos resultados pueden motivar opiniones contradictorias... Algo, por lo demás, perfectamente perceptible en la errática postura seguida por este genetista en sus contradictorias declaraciones a los medios, según acabamos de mostrar.

En efecto, el escaso influjo genético procedente de la estepa eurasiática que Rui Martiniano atribuía a las poblaciones de la Edad del Bronce portuguesa se limitaba al ADN autosómico y mitocondrial (Martiniano et al., 2017, Table 1, Figure 4), algo que por cierto ya se había reconocido característico de las poblaciones actuales de España y Portugal desde hacía unos años (cfr. Haak et al., 2015, Figure 3). Sin embargo, su mismo estudio descubrió una auténtica inflexión en el registro del cromosoma Y (véase Tabla 2).

\begin{tabular}{|c|c|c|}
\hline $\begin{array}{l}\text { CONTEXTO } \\
\text { ARQUEOLÓGICO }\end{array}$ & $\begin{array}{l}\text { YACIMIENTO } \\
\text { ARQUEOLÓGICO }\end{array}$ & $\begin{array}{l}\text { HAPLOGRUPO } \\
\text { (CROMOSOMA Y) }\end{array}$ \\
\hline Neolítico medio & Lugar do Canto & $\mathrm{I}$ \\
\hline \multirow{4}{*}{$\begin{array}{l}\text { Neolítico final } y \\
\text { Calcolítico }\end{array}$} & \multirow{2}{*}{ Cabeço da Arruda } & $\mathrm{I} 2 \mathrm{a} 1 \mathrm{~b}$ \\
\hline & & G2a2a1 \\
\hline & Cova da Moura & $\mathrm{I} 2 \mathrm{a} 1 \mathrm{~b}$ \\
\hline & Dolmen de Ansião & I2a1a1a1b \\
\hline \multirow{3}{*}{$\begin{array}{l}\text { Edad del Bronce } \\
\text { medio }\end{array}$} & $\begin{array}{l}\text { Monte do Gato de } \\
\text { Cima }\end{array}$ & R1b1a2a1a2 \\
\hline & \multirow{2}{*}{ Torre Velha } & R1b1a2 \\
\hline & & R1b1a2a1a2 \\
\hline
\end{tabular}

TABLA 2. Muestras genéticas de la Prehistoria reciente portuguesa (según Martiniano et al., 2017) 
La muestra estadística era minúscula, pero evidenciaba sin mucho margen de discusión una tendencia general muy clara: los linajes masculinos presentes durante el Neolítico y Calcolítico (haplogrupos I y G del cromosoma Y) eran sustituidos en la Edad del Bronce por los dominantes desde entonces hasta hoy (haplogrupo R1b). Múltiples estudios han venido detectando procesos similares a lo largo de la Prehistoria europea, evidenciando la difusión de estos nuevos linajes desde la estepa eurasiática a partir del Calcolítico (Allentoft et al., 2015; Haak et al., 2015; Cassidy et al., 2016; Olalde et al., 2017); y a día de hoy el registro arqueogenético ibérico se ha ampliado a cientos de muestras más que inciden en la misma tendencia (Olalde et al., 2019, especialmente Figure 2B). Es esto precisamente lo que ha llevado, entre otros, a David Reich a interpretar de un modo diametralmente opuesto los mismos datos: para él, este influjo exógeno no sólo sería muy relevante, sino que constituiría el "ejemplo más sorprendente" de su difusión. En efecto, el reemplazamiento de los haplogrupos del cromosoma $\mathrm{Y}$, frente a la remanencia del ADN autosómico y mitocondrial, exacerbaría las implicaciones sociales de este proceso genético, al denotar la mayor capacidad reproductiva, y por ende el mayor poder, de los varones de origen alóctono y sus descendientes (Reich, 2018a y b).

Sea ésta o no una opinión acertada, de lo que ya no cabe duda alguna es de que en la Edad del Bronce ocurrió un proceso demográfico de gran magnitud que alteró para siempre el panorama genético de la península ibérica, dejando su rastro en el ADN de los individuos de aquel entonces, cuya herencia ha llegado hasta hoy. Explorar las causas, mecanismos y consecuencias de este proceso debería formar parte de las inquietudes no sólo de los genetistas, sino también de arqueólogos e historiadores. Y apenas unos años después de que este proceso comenzara a salir a la luz gracias al progreso de la arqueogenética, deberíamos ser lo bastante humildes como para reconocer que aún no sabemos casi nada de él y que todas las vías de investigación están abiertas... Incluso las planteadas por David Reich.

\section{Sobre invasiones, conquistas y exterminios en la Edad del Bronce}

Es así como inevitablemente tropezamos, una vez más, con el manifiesto objeto del presente artículo, que, a propósito de su denuncia contra la supuesta inexactitud del artículo de Manuel Ansede, expresamente descarta varias vías explicativas: 
La utilización de términos como "invasión", "conquista" o "borrar del mapa" no sólo está completamente fuera de contexto en el conocimiento que actualmente se tiene de este periodo prehistórico, sino que es injustificada a la luz de las evidencias empíricas existentes. [...] Ninguna evidencia en los datos científicos conocidos permite en ningún caso hablar de "exterminios", "invasiones" o sociedades "borradas del mapa", simplemente porque ello está totalmente fuera de contexto entre las sociedades del III milenio, por su tecnología, por su organización y por su forma de vida (Valera et al., 2018).

Por dos veces se repite, pues, que las "evidencias empíricas" o "los datos científicos" - entre lo que hoy figura la sustitución general de los linajes masculinos - descartan la incidencia de "invasion(es)", "conquista(s)", "exterminio(s)" o "sociedades borradas del mapa" en la península ibérica del III milenio a.C. La razón aducida es que, supuestamente, tales contingencias estarían "totalmente fuera de[1] contexto" de la "tecnología", la "organización" y la "forma de vida" de aquellas sociedades.

No pretendo ni mucho menos defender las soluciones terminológicas ni las simplificaciones teóricas incurridas por Manuel Ansede en su artículo: de lo que se trata es, por el contrario, de determinar si en este punto la reacción del manifiesto está o no justificada. Por supuesto, es muy relativa la pertinencia del uso de términos como "invasión" o "conquista" en el contexto referido; y no digamos la de expresiones coloquiales como "borrar del mapa". Sin embargo, hace ya cincuenta años que David L. Clarke advirtió que la "ambigüedad e imprecisión de la terminología es una de las mayores restricciones para el avance de la Arqueología" (Clarke, 2015 [1968], p. 23); y tuviera o no razón lo cierto es que desde entonces la diversidad terminológica no sólo no se ha acotado sino que se ha amplificado al amparo de las escuelas posprocesuales... Al menos, la literatura académica no ha dejado de lamentar el mismo problema (por poner un ejemplo entre la bibliografía ya citada, Calo Lourido, 2010, p. 63). Pero aun si hubiera una convención terminológica en Arqueología que fijase el valor de dichos términos — que no la hay—, resultaría cuando menos caprichoso pretender que los medios de comunicación, ajenos al mundo académico, tuvieran de adaptarse a tal convención. Y si donde ponemos el foco es en el fondo y no en la forma del problema, comprobaremos que, al margen de la rimbombante "realidad científica de nuestra Prehistoria" arrogada por los firmantes del manifiesto, existen múltiples "evidencias empíricas" que pueden apoyar la violencia y el reemplazamiento de poblaciones como factor explicativo de las discontinuidades percibidas en el registro genético de la Edad del Bronce ibérica.

En este sentido, en Antropología se asume a menudo que las sociedades «primitivas», incluidas las prehistóricas, no sólo eran más violentas que las 
actuales, sino que mucho más propensas a exterminar a los rivales derrotados. Podemos citar a este respecto a Lawrence H. Keeley, uno de los principales responsables, desde hace más de veinte años, de poner en entredicho el mito del «pasado pacificado»:

En grupos no estatales, los ejemplos de reconocimiento a los derrotados o de toma de prisioneros entre sus varones adultos son en extremo insólitos. Los varones adultos que caían en manos de sus enemigos solían ser inmediatamente ejecutados. [...] Armados o desarmados, los varones adultos eran matados sin vacilación en batallas, incursiones, o en las fugas que seguían a los combates en la gran mayoría de las sociedades primitivas (Keeley, 1996, pp. 83-84).

La suerte de las mujeres, sin embargo, solía ser diferente: su captura formaba parte de las ambiciones que condicionaban la guerra «primitiva» (Keeley, 1996, pp. 85-86). Tales generalizaciones serán más o menos oportunas, pero desde luego no quedan al margen de "la realidad científica de nuestra Prehistoria", ni deben ser omitidas, por tanto, a la hora de tratar de explicar un hecho tan singular como la supervivencia diferencial de los linajes masculinos y femeninos ibéricos a lo largo de la Edad del Bronce.

También la Lingüística tiene su voz en este asunto, que se está asociando cada vez más a la indoeuropeización. A este respecto, los estudios comparativos han dedicado grandes esfuerzos a reconstruir la sociedad indoeuropea común, en la que figuraría el *koryos o "banda guerrera", institución que uniría partidas de jóvenes solteros apartados de su comunidad y dedicados al robo y a actividades bélicas en los confines de la misma (MacCone, 1987; Anthony, 2007, pp. 364365). Más controvertida es la inclusión en la misma categoría del ver sacrum, genuino ritual itálico eventualmente dirigido a expulsar a los varones nacidos durante un determinado año por razones religiosas o económicas. Aunque a menudo se lo ha asociado al pasado indoeuropeo (por ejemplo, Dumézil, 1974, p. 218), no parece haber una base firme para retrotraerlo tan lejos, al menos no en su forma histórica concreta; habiéndose identificado, eso sí, costumbres similares en otros ámbitos de la misma familia lingüística, que habrían condicionado las migraciones célticas y germánicas, e incluso la colonización griega (cfr. Versnel, 1994, p. 307). No parece descabellado pensar que instituciones como estas pudieran haber influido en la expansión de los linajes masculinos procedentes de la estepa eurasiática a lo largo de la Edad del Bronce.

Creo significativo añadir que ambas tradiciones confluyen en la historia de los mamertinos, ítalos que en el siglo III a.C. se hicieron con el control de la ciudad griega de Mesina a traición, mataron a los hombres y tomaron como esposas a las mujeres (Polyb., Hist., I, 7). ¿Quién podría reconstruir estos hechos 
si, prescindiendo de las fuentes escritas, tuviéramos que depender únicamente de la Arqueología? Nos resultaría ininteligible incluso la prístina leyenda Mamertinōn que, precisamente gracias a la Arqueología, se documenta en el numerario siciliota de la época (cfr. Särström, 1940).

Los mamertinos quizá sean un caso único en la expresión tardía de este antiguo sustrato cultural, mejor conocido por la mitología y literatura comparadas. Mas allá donde se conservan, las fuentes históricas insisten en la violencia diferencial ejercida sobre varones y mujeres en las sociedades antiguas. Un experto en historia militar de la Antigüedad como Robert Drews afirma que en la Mesopotamia de la Edad del Bronce las ciudades conquistadas solían sufrir la masacre de su población masculina y la esclavitud de la femenina (Drews, 2017, p. 74). Lo mismo nos sugiere la literatura: el corpus homérico es cuando menos insistente a la hora de describir hechos similares. Si bien resultaría prolijo enumerar todas las citas implicadas, no estará de más reproducir uno de los pasajes que, precisamente por su orientación retórica, mejor condensa nuestro argumento:

Una por una le refirió [Cleopatra a su esposo Meleagro] todas las cuitas que tienen los hombres cuya ciudad es tomada: matan a las gentes, el fuego reduce a cenizas la ciudad y otros se llevan como presa a los niños y a las mujeres de profundas cinturas (Hom., Il., IX, 593-594: ed. Rodríguez Alonso, 1986, p. 213).

Aunque los poemas homéricos fueron compuestos alrededor del siglo VIII a.C., el ciclo épico que materializan se originó en el contexto de la cultura micénica; y en concreto se ha sugerido que la destrucción de Troya, la matanza en masa de sus varones adultos y la reducción de sus mujeres y niños a la esclavitud formaría parte de este primitivo poso literario (Latacz, 2004 [2001], p. 207)... Estamos, en definitiva, ante otro claro reflejo de los usos bélicos de la Edad del Bronce.

Incluso la investigación etológica ha detectado comportamientos similares en otras especies de primates. Ciertamente, si el exterminio organizado de grupos rivales y la captura de hembras jóvenes entra dentro de las capacidades militares de los chimpancés (Goodall, 2010 [1990], p. 119), no parece que ello pueda quedar "totalmente fuera de[1] contexto" de la "tecnología" y la "organización" de las sociedades humanas de la Prehistoria reciente.

Es posible, como explicó una arqueóloga anónima a los medios de comunicación dentro de la polémica que nos ocupa, que el tratamiento de la cuestión de género por Manuel Ansede - recordemos: el mismo exactamente que el de David Reich- denote machismo (Martínez Ron, 2018). Sin embargo, 
descartar su pertinencia en base a una acusación tan genérica y superficial quizá denote también alguna demagogia por su parte, o bien simple desconocimiento de ciertos conceptos antropológicos. En efecto, bajo la matanza de varones y la captura de mujeres - hechos ciertamente puntuales incluso entre las sociedades primitivas más belicosas - subyacen poderosas fuerzas estructurales, dotadas de un valor objetivo que no debemos reducir al mero subjetivismo machista de las observaciones y teorizaciones de los antropólogos-varones-blancos que las hayan podido describir en multitud de sociedades preindustriales: incremento de la violencia intergrupal, exaltación de los valores guerreros y de la masculinidad, exogamia femenina en sistemas de parentesco patrilineales, etcétera. Que la investigación prehistórica valore los indicios y las implicaciones de estas dinámicas sociales parece más una necesidad que un sesgo sexista; pero quien piense lo contrario debería ser consciente de que su supuesto resabio machista no las invalida como un factor objetivo a tener en cuenta para explicar el problema de la transformación genética de nuestra Edad del Bronce.

De hecho, la recién citada exogamia femenina ha comenzado a ser valorada en estudios responsables con la cuestión de género para conciliar el registro genético y arqueológico de la Edad del Bronce antiguo en Europa central: al parecer, la simple movilidad individual de mujeres al contraer matrimonio entre comunidades diferentes matizaría la relevancia de las grandes migraciones como factor explicativo de la historia genética de la región (Knipper et al., 2017). Con todo, contribuciones tan oportunas como esta distan de justificar la desatención a otras posibles variables; y de hecho el conjunto de los factores antes citados parece haber condicionado a menudo influjos demográficos y culturales de escala regional que podrían paralelizarse con nuestro problema. Incluso para esto contamos con reportes etnográficos, como puede volver a ilustrarnos Lawrence H. Keeley, cerrando así el círculo que con él mismo hemos abierto:

Según sus tradiciones, los caribes de las antillas menores habrían conquistado estas islas un siglo antes de Colón exterminando a los varones arahuacos locales y tomando a sus mujeres como esposas (Keeley, 1996, p. 86).

Este relato y la misma identidad caribe de las poblaciones a las que hace referencia ha sido puesta en tela de juicio por la historiografía contemporánea (por ejemplo, Davis y Goodwin, 1990, pp. 38-40). Ahora bien, dentro de nuestros limitados intereses importa señalar que la arqueogenética no ha podido descartarlo. Aunque el mayor estudio emprendido hasta la fecha ha constatado la disparidad genética entre las muestras de ADN antiguo obtenidas de las antillas menores y los caribes actuales del continente, esto se ha hecho sobre un análisis 
muy fragmentario del cromosoma Y. De hecho, sus firmantes han concluido que sigue abierta la puerta a un flujo tardío de migrantes del continente (Mendisco et al., 2014, pp. 5-7), en consonancia con la difusión en pleno siglo XV del horizonte cerámico Kalina (Allaire, 1984) y del propio relato caribe al que hemos aludido. Quizá en el futuro la arqueogenética pueda zanjar este asunto, pues detectar en el Caribe una fracción del influjo genético externo que se ha documentado en la Edad del Bronce europea verificaría una leyenda aborigen que, cuando menos, hace ensombrecer el artículo de Manuel Ansede.

Mas volvamos al Viejo Mundo, a la Edad del Bronce y a la Arqueología académica. Y hagámoslo en relación a una de las voces actuales más críticas contra los principios comunes de los estudios indoeuropeos en general y la hipótesis de la estepa en particular; ámbito que refleja tan bien la difícil imbricación disciplinar entre Arqueología, Lingüística y, últimamente, Genética. En efecto, llama la atención que un arqueólogo de la talla de Jean-Paul Demoule, tras más de medio millar de páginas de su iconoclasta pero fundamentadísimo libro Mais où sont passés les Indo-Européens? — con un tratamiento, eso sí, francamente decepcionante de la cuestión genética (cfr. Demoule, 2017 [2014], pp. 355-358) - , no se haya acercado ni de lejos al categorismo de los firmantes del manifiesto que nos ocupa; dejando, por el contrario, la puerta abierta a sus pretendidas refutaciones:

El modelo global que queda por construir [para la indoeuropeización ...] habrá de ser ciertamente muy complejo: se imbricarán, repartidos sobre una larga duración de tiempo, los fenómenos de difusión, de mestizaje, de aculturación, de convergencias, e incluso de conquistas (Demoule, 2017 [2014], p. 664).

¡Conquistas! ¿Acaso Jean-Paul Demoule, antítesis de los presupuestos invasionistas contenidos en el artículo de Manuel Ansede, quedará también fuera de la "realidad científica de nuestra Prehistoria"? Nada más lejos de la realidad: lo cierto es que, contra la postura de los firmantes del manifiesto, todas las evidencias apuntan a que la tecnología, organización social y forma de vida de las sociedades del III milenio a.C. les conferían la capacidad de perpetrar «conquistas»e «invasiones», e incluso de «exterminar»a otras poblaciones. El plural utilizado tanto aquí como ocasionalmente en el manifiesto no está exento de significancia. Evidentemente, en los milenios III y II a.C. no existía entidad socio-política alguna capaz de llevar a cabo «una» invasión de la península ibérica y perpetrar «el» exterminio de sus habitantes. Pero las unidades sociales que componían cualquier cultura de aquel entonces sí eran capaces de realizar campañas armadas a pequeña escala contra otras, conquistarlas y ocasionalmente 
destruirlas físicamente. Ante el hecho constatado por la arqueogenética, el simple reemplazamiento de los linajes masculinos, ni siquiera la destrucción generalizada de asentamientos - sólo excepcionalmente permanentes, y apenas conocidos en muchas regiones de la península ibérica - conforma un requisito indispensable para sustentar una hipótesis de este tipo: baste recordar a los mamertinos. Puede, en definitiva, que el registro arqueológico no permita calibrar tales contingencias en nuestra Prehistoria, pero ello no implica que las "evidencias empíricas" las descarten, pues la lógica argumental establece que ningún hecho puede probarse ex silentio.

No me cabe duda de que los firmantes del manifiesto, algunos de los cuales destacados precisamente en «despacificar el pasado» de sus respectivos campos de investigación (por ejemplo, Cámara Serrano, 2001; Parcero Oubiña, 2002), son conscientes de todo lo que acabo de exponer. De hecho, en un artículo sobre arqueología de la violencia firmado por tres de ellos se descarta no sólo que su disciplina pueda responder a la pregunta "¿cuál fue el grado de la intensidad de la violencia en la Prehistoria?", sino su misma pertinencia, arguyendo que los intereses de la Arqueología en relación a este tema han de ser otros, orientados a sus interrelaciones sociales y culturales (Lull et al., 2006, p. 104). Y, sin embargo, han pretendido acallar a un periodista que difundió, de un modo más o menos oportuno, una explicación basada en la violencia y el desplazamiento de pueblos para un problema científico recién planteado... Una explicación, cabe añadir, que, lejos de contradecir el conocimiento arqueológico, podría complementar algunas de sus constataciones. El desarrollo a lo largo del II milenio a.C. en toda la península ibérica de la «revolución de los productos secundarios», de sistemas patriarcales de fuerte éthos guerrero, o de marcadores de élite como la orfebrería o las espadas (cfr. Gálvez Priego, 1992), guarda en conjunto una correspondencia ineludible no sólo con el nuevo panorama genético constatado, sino también con el paquete cultural «estándar» típico —o tópico, según se mire - de la indoeuropeización.

Si ningún hecho probado entra realmente en conflicto con el fondo del artículo de Manuel Ansede, sólo dos razones de carácter disciplinar se perfilan ante la reacción suscitada. La primera es que lo sugerido en tal artículo no suena a nuevo sino a viejo, y concretamente al «invasionismo» del siglo pasado. Desde entonces, el fenómeno migratorio ha estado prácticamente ausente del discurso científico de la Arqueología occidental (Anthony, 2007, p. 17). En segundo lugar, la recuperación desde otra disciplina, la Genética, del viejo discurso «migracionista» genera rechazo a quienes estaban acostumbrados a un consenso tácito de más de medio siglo en Arqueología... O sea, simple corporativismo 
disciplinar: una razón a la que ya hemos aludido y que no tarda en perfilarse ante cualquier observador externo del problema (Callaway, 2018; Galán, 2018).

Probablemente sea inevitable que los proyectos interdisciplinares conlleven fricciones entre las disciplinas implicadas. Sin embargo, la literatura académica ha detectado hace tiempo un sesgo evitable que suele operar en este asunto: la confusión de los paradigmas disciplinares con la propia realidad; cuando aquellos, de hecho, deberían flexibilizarse en proyectos de este tipo, en la medida en que la interdisciplinariedad rebasa el ámbito estricto de una sola disciplina (Bella y Williamson, 1976, p. 109)... Ciertamente, al ampararse en la "realidad científica de nuestra Prehistoria", los firmantes del manifiesto no han hecho sino convertir en explícito lo que ya de por sí era evidente.

\section{Arqueología, genética, e interdisciplinariedad}

Dentro de poco se cumplirán cuarenta años desde que los Alvarez, junto con dos colegas químicos, formularan por primera vez la teoría del impacto como explicación de la extinción masiva del Cretáceo-Paleógeno (Alvarez et al., 1980). Aunque Walter Alvarez (Jr.) es geólogo, ninguno de los proponentes originales había destacado anteriormente en Paleontología. Y sin embargo es obvio que hoy ningún paleontólogo, incluso crítico con la teoría, intentaría explicar la extinción de los dinosaurios al margen del asteroide que hace unos 65 millones de años impactó sobre Chicxulub.

Hoy hay genetistas que tratan de explicar un fenómeno recién descubierto, la transformación genética de Europa en el Calcolítico y la Edad del Bronce, por medio de conceptos que parecen desenterrar el caduco «invasionismo» de principios del siglo XX. «Invasiones», «conquistas» y «exterminios» son a todas luces explicaciones demasiado simplistas $\mathrm{y}$, aunque macabras, quizá algo ingenuas; pero no necesariamente más que la «causa extraterrestre» de la extinción de los dinosaurios. A los arqueólogos corresponde, como entonces correspondió a los paleontólogos, someter a verificación las nuevas hipótesis surgidas al amparo de otras disciplinas. Habrá que conciliar así los datos arqueológicos con los arqueogenéticos, pero también con los históricos, literarios, lingüísticos y antropológicos que superficialmente hemos atendido a lo largo de este artículo; e incluso con los de otras disciplinas a las que ni siquiera hemos rozado, como la epidemiología, que también comienza a tratar de aportar su granito de arena (por ejemplo, Rasmussen et al., 2015). Este problema demanda en definitiva discusión interdisciplinar sosegada y sin prejuicios, que de hecho ya han abierto algunos arqueólogos, incluso desde posturas muy críticas 
con los presupuestos de los genetistas (Heyd, 2017; Furholt, 2018; Klejn et al., 2018). A nada de ello se parece la simple recusación ex cathedra, y para más inri dirigida contra el mensajero y no contra el responsable, que ha tenido lugar en el manifiesto que nos ocupa. ¿Qué pensaríamos hoy de un paleontólogo que en 1980 tratase de desautorizar a los medios que se hicieron eco de la teoría de los Alvarez sobre la base de ser ajena a "la realidad científica de nuestra Prehistoria"?... Tal será el lugar, me temo, que la Historia de la Ciencia reserve al manifiesto que nos ocupa y a las lamentables inercias que éste deja entrever en la Arqueología hispano-portuguesa actual.

Ahora bien, los firmantes del mismo han definido expresamente la arqueogenética como "una de las novedades más potentes y de más profundo efecto" en la investigación arqueológica actual, aprovechando, con todo, para reclamar la última palabra:

Es la Arqueología la que proporciona los datos y las garantías de calidad contextual para que, mediante la interdisciplinariedad, los datos arqueogenéticos resulten significativos y relevantes, y es mediante su integración con los datos arqueológicos como los datos arqueogenéticos adquieren una relevancia que por sí solos no tienen (Valera et al., 2018).

Una vez más, no cabría objeción alguna a este correctísimo texto si no fuera por su contexto. Lo cierto es que un dato arqueogenético es, por definición, interdisciplinar; y sin duda el genetista implicado, David Reich, trató de conciliar lo mejor que pudo los datos de su disciplina con los arqueológicos para elaborar su visión particular sobre el asunto... Y a priori, un genetista puede emplear tan bien - o tan mal - los datos arqueológicos como un arqueólogo los datos genéticos.

Mas si es verdad que es sólo la Arqueología quien tiene la capacidad de ofrecer una respuesta a los problemas planteados por el ADN antiguo, ¿por qué no lo hace? El año pasado han salido varios libros divulgativos firmados por genetistas que tratan de explicar sus descubrimientos sobre la Prehistoria europea más allá de sus investigaciones académicas, de carácter más técnico, valiéndose extensivamente para ello de datos arqueológicos del todo ajenos a su disciplina (Reich, 2018a; Lalueza-Fox, 2018). Por supuesto, los lingüistas han comenzado a incorporar la arqueogenética a sus modelos sobre la expansión de las lenguas indoeuropeas; lo cual quizá no resulte sorprendente, pues los nuevos datos vienen precisamente a apoyar la teoría estándar vigente para ellos (por ejemplo, Kortlandt, 2018). Y contamos ya con una tesis doctoral leída en una universidad española que se ha preocupado por conjugar los datos genéticos, arqueológicos y 
lingüísticos para confeccionar un modelo interpretativo más sobre la expansión de las lenguas indoeuropeas: no la firmó un doctorando de Prehistoria o Arqueología, sino ¡de Medicina! (Quiles, 2017). ¿Para cuándo una síntesis firmada por un arqueólogo que intente digerir el registro genético?

Las interpretaciones ofrecidas por genetistas sobre la Prehistoria europea pueden parecernos mejores o peores, pero son lo que tenemos ante el total desdén que la mayoría de los arqueólogos ha venido mostrado hacia los descubrimientos de la arqueogenética; lo cual, por desgracia, ha culminado en abierta e irreflexiva oposición a quienes comienzan a tratar de cambiar esto desde otros ámbitos disciplinares. La relación entre arqueólogos y genetistas no debería consistir en que los primeros entreguen muestras orgánicas a los segundos para que las analicen, y después protesten porque también las interpreten, prácticamente sin proponer nada más que encerrar los datos en un cajón. En este sentido, una antropóloga molecular, Ann Horsburgh, ha denunciado ante los medios la tendencia de algunos arqueólogos a limitarse a contactar a los genetistas y enviarles muestras, sin ofrecer ni exigir nada más que una publicación de impacto, desatendiendo incluso la discusión de los resultados. "Eso no es colaboración", ha concluido (Callaway, 2018). Y ciertamente tampoco es interdisciplinariedad, que según su definición clásica por Jean Piaget requiere reciprocidad y enriquecimiento mutuo: es, por el contrario, el nivel más precario de la colaboración entre disciplinas científicas, en que éstas actúan por separado y en relación asimétrica (Piaget, 1972). Ojalá desde las ciencias humanas recapacitemos sobre si estamos afrontando de manera adecuada la colaboración con otras disciplinas científicas y el aprovechamiento de los datos que ésta ya comienza a ofrecernos, sobre la base de la "tolerancia recíproca entre disciplinas, [...] sin renunciar con todo a su [nuestra] identidad" (Darbellay, 2011, p. 84).

Y ello, a pesar de que la genética pueda ser peligrosa. De hecho, ya lo está siendo... Aunque sobre todo para la credibilidad de quienes pretenden seguir viviendo de espaldas a ella.

\section{Referencias bibliográficas}

Alinei, M. 2008. A teoria da continuidade paleolítica das origens indoeuropeias: uma introdução. Lisboa: Apenas Livros.

Allaire, L. 1984. "A reconstruction of early historical island Carib pottery". Southeastern Archaeology 3 (2): 121-133. 
Allentoft, M. E., M. Sikora, K.-G. Sjögren, S. Rasmussen, M. Rasmussen, J. Stenderup, P. B. Damgaard, H. Schroeder, T. Ahlström, L. Vinner, A.-S. Malaspinas, A. Margaryan, T. Higham, D. Chivall, N. Lynnerup, L. Harvig, J. Baron, P. Della Casa, P. Dąbrowski, P. R. Duffy, A. V. Ebel, A. Epimakhov, K. Frei, M. Furmanek, T. Gralak, A. Gromov, S. Gronkiewicz, G. Grupe, T. Hajdu, R. Jarysz, V. Khartanovich, A. Khokhlov, V. Kiss, J. Koláŕ, A. Kriiska, I. Lasak, C. Longhi, G. McGlynn, A. Merkevicius, I. Merkyte, M. Metspalu, R. Mkrtchyan, V. Moiseyev, L. Paja, G. Pálfi, D. Pokutta, Ł. Pospieszny, T. D. Price, L. Saag, M. Sablin, N. Shish-lina, V. Smrčka, V. I. Soenov, V. Szeverényi, G. Tóth, S. V. Trifanova, L. Varul, M. Vicze, L. Yepiskoposyan, V. Zhitenev, L. Orlando, T. Sicheritz-Pontén, S. Brunak, R. Nielsen, K. Kristiansen y E. Willerslev. 2015. "Population genomics of bronze age Eurasia”. Nature 522 (7555): 167-172.

https://doi.org/10.1038/nature14507

Alvarez, L. W., W. Alvarez, F. Asero y H. V. Michel. 1980. "Extraterrestrial Cause for the Cretaceous-Tertiary Extinction". Science 208 (4448): 10951108. https://doi.org./10.1126/science.208.4448.1095

Ansede, M. 2018. "Una invasión borró del mapa a los hombres de la península Ibérica hace 4.500 años". El Pais, 2 de octubre.

https://elpais.com/elpais/2018/10/01/ciencia/1538416630_736638.html de enero de 2019).

Anthony, D. W. 2007. The Horse, the Wheel, and Language: How Bronze-Age Riders from the Eurasian Steppes Shaped the Modern World. PrincetonOxford: Princeton University Press.

Azurmendi, N. 2011. "Los antepasados de los británicos no son los celtas, sino los vascos". El Diario Vasco, 12 de mayo. https://www.diariovasco.com/v/20110512/al-dia-local/antepasadosbritanicos-celtas-sino-20110512.html (14 de enero de 2019).

Bella, D. A. y K. J. Williamson. 1976. "Conflicts in interdisciplinary research". Journal of Environmental Systems, 6 (2): 105-124.

Brotherton, P., W. Haak, J. Templeton, G. Brandt, J. Soubrier, C. J. Adler, S. M. Richards, C. Der Sarkissian, R. Ganslmeier, S. Friedrich, V. Dresely, M. van Oven, R. Kenyon, M. B. Van der Hoek, J. Korlach, K. Luong, S. Y. W. Ho, L. Quintana-Murci, D. M. Behar, H. Meller, K. W. Alt, A. Kooper, The Geographic Consortium. 2013. "Neolithic mitochondrial haplogroup $\mathrm{H}$ genomes and the genetic origins of Europeans". Nature Communications, 4 (1764). https://www.nature.com/articles/ncomms2656 (5 de agosto de 2019). 
Callaway, E. 2018. "Divided by DNA: The uneasy relationship between archaelogy and ancient genomics". Nature, 555 (7698). https://www.nature.com/articles/d41586-018-03773-6 (14 de enero de 2019).

Calo Lourido, F. 2010. Os celtas: unha (re)visión dende Galicia. Vigo: Xerais.

Cámara Serrano, J. A. 2001. El ritual funerario en la Prehistoria reciente en el sur de la península ibérica. Oxford: Archaeopress.

Cassidy, L. M., R. Martiniano, E. M. Murphy, M. D. Teasdale, J. Mallory, B. Hartwell y D. G. Bradley. 2016. "Neolithic and Bronze Age migration to Ireland and the establishment of the insular Atlantic genome". Proceedings of the National Academy of Sciences, 113 (2): 368-373.

https://doi.org/10.1073/pnas.1518445113

Clarke, D. L. 2015 [1968]. Analytical Archaeology. Oxon: Routledge.

Conde, M. 2006. "Una teoría de investigadores italianos sitúa en Galicia la cuna del mundo celta". La Voz de Galicia, 20 de octubre.

https://www.lavozdegalicia.es/noticia/sociedad/2006/10/20/teoria-

investigadores-italianos-situa-galicia-cuna-mundo-celta/0003_5211444.htm (14 de enero de 2019).

Darbellay, F. 2011. "Vers une théorie de l'interdisciplinarité? Entre unité et diversité". Nouvelles Perspectives en Sciences Sociales, 7 (1): 65-87. https://doi.org/10.7202/1007082ar

David, D. D. y R. C. Goodwin. 1990. "Island Carib Origins: Evidence and Nonevidence". American Antiquity, 55 (1): 37-48.

Demoule, J.-P. 2017 [2014]. Mais où sont passés les Indo-Européens?: le mythe d'origine de l'Occident. París: Éditions du Seuil.

Drews, R. 2017. Militarism and the Indo-Europeanizing of Europe. LondresNueva York: Routledge.

Dumézil, G. 1974. La réligion romaine archaïque. París: Payot.

Firmino, T. 2017. "Como o genoma de 14 esqueletos portugueses antigos conta a história das invasões da Idade do Bronze". Público, 27 de julio.

https://www.publico.pt/2017/07/27/ciencia/noticia/como-o-genoma-de-14esqueletos-portugueses-antigos-conta-a-historia-das-invasoes-na-idade-dobronze-1780549 (14 de enero de 2019).

Franz, A. 2017. "Invasion aus Osten: Was Migranten uns vor Jahrtausenden brachten". NZZ am Sonntag, 30 de junio. https://nzzas.nzz.ch/wissen/invasion-aus-osten-was-migranten-archaeologieschnurkeramik-ld.1303563?reduced=true (14 de enero de 2019).

Furholt, M. 2018. "Massive migrations? The impact of recent aDNA studies on our view of third millennium Europe". European Journal of Archaeology, 21

(2): 159-191. https://doi.org/10.1017/eaa.2017.43 
Galán, L. 2018. "Enigmas de la Prehistoria”. El País, 14 de octubre. https://elpais.com/elpais/2018/10/12/opinion/1539345411_768224.html (14 de enero de 2019).

Goodall, J. 2010 [1990]. Through a Window: My Thirty Years with the Chimpanzees of Gombe. Boston-Nueva York: Mariner Books.

Haak, W., I. Lazaridis, N. Patterson, N. Rohland, S. Mallick, B. Llamas, G. Brandt, S. Nordenfelt, E. Harney, K. Stewardson, Q. Fu, A. Mittnik, E. Bánffy, C. Economou, M. Francken, S. Friederich, R. Garrido Pena, F. Hallgren, V. Khartanovich, A. Khokhlov, M. Kunst, P. Kuznetsov, H. Meller, O. Mochalov, V. Moiseyev, N. Nicklisch, S. L. Pichler, R. Risch, M. A. Rojo Guerra, C. Roth, A. Szécsényi-Nagy, J. Wahl, M. Meyer, J. Krause, D. Brown, D. Anthony, A. Cooper, K. W. Alt y D. Reich. 2015. "Massive migration from the steppe was a source for Indo-European languages in Europe". Nature 522 (7555): 207-211. https://doi.org/10.1038/nature14317

Hervella, M., N. Izagirre, S. Alonso, R. Fregel, A. Alonso, V. M. Cabrera, C. de la Rúa. 2012. "Ancient DNA from Hunter-Gatherer and Farmer Groups from Northern Spain Supports a Random Dispersion Model for the Neolithic Expansion into Europe". PLoS One, 7 (4): e34417. https://doi.org/10.1371/journal.pone.0034417 (5 de agosto de 2019).

Heyd, V. 2017. "Kossinna's smile”. Antiquity, 91 (356): 348-359.

https://doi.org/10.15184/aqy.2017.21

Kahn, J., A. Nelson, J. L. Graves, S. Abel, R. Benjamin, S. Blacker, C. Bliss, L. Braun, K. M. Bridges, C. Calhoun, C. Chaufan, N. Comfort, R. Cone, R. Cooper, M. Darnovsky, R. Desalle, T. Duster, A. Fausto-Sterling, A. Fuentes, J. H. Fujimura, S. M. Fullerton, D. Fullwiley, O. Gokcumen, A. Goodman, M. H. Green, E. Hagelberg, E. Hammonds, H. Hansen, J. Hartigan, A. Hatch, T. Heinemann, J. Kaufman, T. Keaton, T. Keel, N. Krieger, S. Krimsky, J. R. Kyllingstad, C. Lee, A. Lefkaditou, S. S.-J. Lee, J. Marks, A. M'charek, M. Montoya, A. Morning, O. K. Obasogie, P. N. Ossorio, T. Platt, R. Pollack, A. Panofsky, K. Paul-Emile, R. M. Rajagopalan, R. Rapp, J. Reardon, A. Morris-Reich, S. M. Reverby, J. A. Richeson, S. S. Richardson, D. Roberts, W. D. Roth, C. D. M. Royal, D. Rutherford, J. K. Shim, K.-S. Taussig, C. Thompson, F. W. Twine, K. Wailoo, P. J. Williams y M. Yudell. 2018. How Not To Talk About Race And Genetics (carta abierta).

https://www.buzzfeednews.com/article/bfopinion/race-genetics-david-reich (14 de enero de 2019).

Keeley, L. H. 1996. War before Civilization: the Myth of the Peaceful Savage.

Nueva York-Oxford: Oxford University Press. 
Klejn, L. S., W. Haak, I. Lazaridis, N. Patterson, D. Reich, K. Kristiansen, K.-G. Sjögren, M. Allentoft, M. Sikora y E. Willerslev. 2018. "Discussion: Are the Origins of Indo-European Languages Explained by the Migration of the Yamnaya Culture to the West?". European Journal of Archaeology 21 (1): 317.

Knipper, C., A. Mittnik, K. Massy, C. Kociumaka, I. Kucukkalipci, M. Maus, F. Wittenborn, S. E. Metz, A. Staskiewicz, J. Krause y P. W. Stockhammer. 2017. "Female exogamy and gene pool diversification at the transition from the Final Neolithic to the Early Bronze Age in central Europe". Proceedings of the National Academy of Sciences 114 (38): 10083-10088. https://doi.org/10.1073/pnas.1706355114

Kortlandt, F. 2018. "The Expansion of the Indo-European Languages". Journal of Indo-European Studies 46 (1-2): 219-231.

Lalueza-Fox, C. 2018. La Forja Genética de Europa: Una Nueva Visión del Pasado de las Poblaciones Humanas. Barcelona: Universitat de Barcelona.

Latacz, J. 2004 [2001]. Troy and Homer: Towards a Solution of an Old Mystery. Oxford-Nueva York: Oxford University Press.

Levy-Coffman, E. 2005. "We are not our ancestors: evidence for discontinuity between prehistoric and modern Europeans". Journal of Genetic Genealogy 1: 40-50.

Lull, V., R. Micó, C. Rihuete y R., Risch. 2006. "La investigación de la violencia: una aproximación desde la Arqueología". Cypsela 16: 87-108.

MacCone, K. 1987. "Hund, Wolf und Krieger bei den Indogermanen". En W. Meid (ed.). Studien zum Indogermanischen Wortschatz. Innsbruck: Institut für Sprachwissenschaft, pp. 101-154.

Marshall, M. 2018. "Every man in Spain was wiped out 4500 years ago by hostile invaders". New Scientist, 28 de septiembre. https:/www.newscientist.com/article/2180923-every-man-in-spain-waswiped-out-4500-years-ago-by-hostile-invaders/ (14 de enero de 2019).

Martínez Ron, A. 2018. "No, nadie exterminó a los hombres de la península ibérica hace 4.500 años". Vozpópuli, 5 de octubre. https://www.vozpopuli.com/altavoz/next/nadie-extermino-hombrespeninsula-hace_0_1178883504.html (14 de enero de 2019).

Martiniano, R., L. M. Cassidy, R. Ó’Maoldúin, R. McLaughlin, N. M. Silva, L. Manco, D. Fidalgo, T. Pereira, M. J. Coelho, M. Serra, J. Burger, R. Parreira, E. Moran, A. C. Valera, E. Porfirio, R. Boaventura, A. M. Silva, D. G. Bradley. 2017. "The population genomics of archaeological transition in west Iberia: Investigation of ancient substructure using imputation and haplotype- 
based methods". Plos Genetics, 13 https://doi.org/10.1371/journal.pgen.1006852

Mendisco, F., M. H. Pemonge, E. Leblay, T. Romon, G. Richard, P. Courtaud y M. F. Deguilloux. 2015. "Where are the Caribs? Ancient DNA from Ceramic Period Human Remains in the Lesser Antille"s. Philosophical Transactions of the Royal Society B 370: 20130388.

https://doi.org./10.1098/rstb.2013.0388

McKie, R. 2017. "Did Dutch hordes kill off the early Britons who started Stonehenge?". The Guardian, 21 de mayo. https://www.theguardian.com/uk-news/2017/may/20/dutch-invadersstonehenge-ancient-britons (14 de enero de 2019).

Olalde, I., S. Brace, M. E. Allentoft, I. Armit, K. Kristiansen, T. Booth, N. Rohland, S. Mallick, A. Szécsényi-Nagy, A. Mittnik, E. Altena, M. Lipson, I. Lazaridis, T. K. Harper, N. Patterson, N. Broomandkhoshbacht, Y. Diekmann, Z. Faltyskova, D. Fernandes, M. Ferry, E. Harney, P. de Knijff, M. Michel, J. Oppenheimer, K. Stewardson, A. Barclay, K. W. Alt, C. Liesau, P. Ríos, C. Blasco, J. Vega Miguel, R. Menduiña García, A. Avilés Fernández, E. Bánffy, M. Bernabò-Brea, D. Billoin, C. Bonsall, L. Bonsall, T. Allen, L. Büster, S. Carver, L. Castells Navarro, O. E. Craig, G. T. Cook, B. Cunliffe, A. Denaire, K. E. Dinwiddy, N. Dodwell, M. Ernée, C. Evans, M. Kuchařík, J. Francès Farré, C. Fowler, M. Gazenbeek, R. Garrido Pena, M. Haber-Uriarte, E. Haduch, G. Hey, N. Jowett, T. Knowles, K. Massy, S. Pfrengle, P. Lefranc, O. Lemercier, A. Lefebvre, C. Heras Martínez, V. Galera Olmo, A. Bastida Ramírez, J. Lomba Maurandi, T. Majó, J. I. McKinley, K. McSweeney, B. G. Mende, A. Modi, G. Kulcsár, V. Kiss, A. Czene, R. Patay, A. Endrődi, K. Köhler, T. Hajdu, T. Szeniczey, J. Dani, Z. Bernert, M. Hoole, O. Cheronet, D. Keating, P. Velemínský, M. Dobeš, F. Candilio, F. Brown, R. Flores Fernández, A.-M. Herrero-Corral, S. Tusa, E. Carnieri, L. Lentini, A. Valenti, A. Zanini, C. Waddington, G. Delibes, E. Guerra-Doce, B. Neil, M. Brittain, M. Luke, R. Mortimer, J. Desideri, M. Besse, G. Brücken, M. Furmanek, A. Hałuszko, M. Mackiewicz, A. Rapiński, S. Leach, I. Soriano, K. T. Lillios, J. L. Cardoso, M. P. Pearson, P. Włodarczak, T. D. Price, P. Prieto, P.-J. Rey, R. Risch, M. A. Rojo Guerra, A. Schmitt, J. Serralongue, A. M. Silva, V. Smrčka, L. Vergnaud, J. Zilhão, D. Caramelli, T. Higham, M. G. Thomas, D. J. Kennett, H. Fokkens, V. Heyd, A. Sheridan, K.-G. Sjögren, P. W. Stockhammer, J. Krause, R. Pinhasi, W. Haak, I. Barnes, C. Lalueza-Fox y D. Reich. 2017. "The Beaker phenomenon and the genomic transformation of northwest Europe". Nature 555 (7695). https://doi.org./10.1038/nature25738 
Olalde, I., S. Mallick, N. Patterson, N. Rohland, V. Villalba-Mouco, M. Silva, K. Dulias, C. J. Edwards, F. Gandini, M. Pala, P. Soares, M. Ferrando-Bernal, N. Adamski, N. Broomandkhoshbacht, O. Cheronet, B. J. Culleton, D. Fernandes, A. M. Lawson, M. Mah, J. Oppenheimer, K. Stewardson, Z. Zhang, J. M. Jiménez Arenas, I. J. Toro Moyano, D. C. Salazar-García, P. Castanyer, M. Santos, J. Tremoleda, M. Lozano, P. García Borja, J. Fernández-Eraso, J. A. Mujika-Alustiza, C. Barroso, F. J. Bermúdez, E. Viguera Mínguez, J. Burch, N. Coromina, D. Vivó, A. Cebrià, J. M. Fullola, O. García Puchol, J. I. Morales, F. X. Oms, T. Majó, J. M. Vergès, A. DíazCarvajal, I. Ollich-Castanyer, F. J. López-Cachero, A. M. Silva, C. AlonsoFernández, G. Delibes de Castro, J. Jiménez Echevarría, A. MorenoMárquez, G. Pascual Berlanga, P. Ramos-García, J. Ramos-Muñoz, E. Vijande Vila, G. Aguilella Arzo, A. Esparza Arroyo, K. T. Lillios, J. Mack, J. Velasco-Vázquez, A. Waterman, L. B. de Lugo Enrich, M. Benito Sánchez, B. Agustí, F. Codina, G. de Prado, A. Estalrrich, A. Fernández Flores, C. Finlayson, G. Finlayson, S. Finlayson, F. Giles-Guzmán, A. Rosas, V. Barciela González, G. García Atiénzar, M. S. Hernández Pérez, A. Llanos, Y. Carrión Marco, I. Collado Beneyto, D. López-Serrano, M. Sanz Tormo, A. C. Valera, C. Blasco, C. Liesau, P. Ríos, J. Daura, M. J. de Pedro Michó, A. A. Diez-Castillo, R. Flores Fernández, J. Francès Farré, R. Garrido-Pena, V. S. Gonçalves, E. Guerra-Doce, A. M. Herrero-Corral, J. Juan-Cabanilles, D. López-Reyes, S. B. McClure, M. Merino Pérez, A. Oliver Foix, M. Sanz Borràs, A. C. Sousa, J. M. Vidal Encinas, D. J. Kennett, M. B. Richards, K. W. Alt, Wolfgang Haak, R. Pinhasi, C. Lalueza-Fox, D. Reich. 2019. "The genomic history of the Iberian Peninsula over the past 8000 years". Science 363: 1230-1234. https://doi.org./10.1126/science.aav4040

Oppenheimer, S. 2007. The Origins of the British. Londres: Robinson.

Parcero Oubiña, C. 2002. La Construcción del Paisaje Social en la Edad del Hierro del Noroeste Ibérico. Ortigueira: Ortegalia-CSIC.

Parzinger, H., W. Willems, J.-P. Demoule, R. Schild, V. Nikolov, A. Harding, M. Heyworth. 2006. Declaration (carta abierta). https://web.archive.org/web/20110717134402/http://www.e-aa.org/statement.pdf (14 de enero de 2019).

Piaget, J. 1972. "L'épistémologie des relations interdisciplinaires". En AA.VV. L'interdisciplinarité: problèmes d'enseignement et de recherche dans les universités. París: OCDE, pp. 131-141.

Quiles, C., 2017. Indo-European demic diffusion model. Tesis doctoral inédita, Universidad de Extremadura. 
Rasmussen, S., M. E. Allentoft, K. Nielsen, L. Orlando, M. Sikora, K.-G. Sjögren, A. G. Pedersen, M. Schubert, A. van Dam, C. M. O. Kapel, H. B. Nielsen, S. Brunak, P. Avetisyan, A. Epimakhov, M. Viktorovich Khalyapin, A. Gnuni, A. Kriiska, I. Lasak, M. Metspalu, V. Moiseyev, A. Gromov, D. Pokutta, L. Saag, L. Varul, L. Yepiskoposyan, T. Sicheritz-Pontén, R. A. Foley, M. Mirazón Lahr, R. Nielsen, K. Kristiansen y E. Willerslev. 2015. "Early divergent strains of Yersinia pestis in Eurasia 5,000 years ago". Cell 163: 571-582. http://dx.doi.org/10.1016/j.cell.2015.10.009

Reich, D. 2018a. Who we are and how we got here: Ancient DNA and the New Science of the Human Past. Nueva York: Pantheon.

Reich, D. 2018b. "Social Inequality Leaves a Genetic Mark: when genetic structure follows social structure". Nautilus, 29 de mayo. http://nautil.us/issue/58/self/social-inequality-leaves-a-genetic-mark (14 de enero de 2019).

Rincon, P. 2018. "Ancient Britons replaced by newcomers". BBC News, 21 de febrero. https://www.bbc.com/news/science-environment-43115485 (14 de enero de 2019).

Rodríguez Alonso, C. 1986. Homero: la Ilíada. Madrid: Akal.

Ruiz-Gálvez Priego, M. 1992. "La novia vendida: orfebrería, herencia y agricultura en la Protohistoria de la Península Ibérica". Spal, 1: 219-252.

Särström, M. 1940. A Study in the Coinage of the Mamertines. Lund: Gleerups Förlag.

Sykes, B. 2006. The Blood of the Isles. Londres: Bantam Press.

Valera, A. C., F. Criado Boado, L. García Sanjuán, S. Lopes, V. S. Gonçalves, J. L. Cardoso, G. Delibes de Castro, M. Rojo Guerra, P. Bueno Ramírez, R. Fábregas Valcarce, J. M. Fullola Pericot, J. C. Martín de la Cruz, C. González Wagner, F. Contreras Cortés, M. Bartelheim, J. Barrio Martin, A. Esparza Arroyo, J. Rodríguez Vidal, J. L. Ubera Jiménez, J. Bernabéu, C. Blasco Bosqued, P. Díaz del Río, J. Vicent García, M. I. Martínez Navarrete, C. Parcero Oubiña, A. González-Ruibal, C. L. von Lettow Vorbeck, J. C. Senna-Martinez, I. Grau Mira, J. Lomba Maurandi, J. B. López Melcio, F. Carrera Ramírez, A. Arizaga Castro, R. Micó Pérez, T. Orozco Köhler, C. Mata Parreño, J. A. Barceló Álvarez, R. Risch, C. Rihuete Herrada, A. Delgado Hervás, R. Barroso Bermejo, J. A. Cámara Serrano, F. Carrión Méndez, G. Aranda Jimenez, J. E. Márquez Romero, A. Hernando Gonzalo, J. Álvarez Sanchís, J. A. Pérez Macías, A. M. Silva, A. Faustino Carvalho, S. Monteiro Rodrigues, R. Garrido Pena, J. Antonio Ruiz Gil, B. Comenda, P. Ríos Mendoza, X.-L. Armada Pita, C. Tejedor, D. González Álvarez, R. Vilaça, A. C. Sousa, M. Diniz, A. Blanco González, J. Soares, C. T. da Silva, 
R. Mataloto, L. S. Evangelista, F. Almeida, J. A. Martín Ruiz, C. Costeira, F. Rodrigues, J. Muralha, M. Serra, R. M. Godinho, M. Lago, N. Cabaço, A. Donnas-Botto, J. F. Fabián García, J. A. G. Guimarães, J. Suárez Otero, P. Jordão, V. Filipe, R. Villalobos García, J. Feio, R. Oliveira, G. Pereira Rosa, A. Pajuelo Pando, J. Suárez Padilla, A. Pereira, A. Ribeiro, A. C. Araújo y S. Gomes. 2018. Genética de una fake news (carta abierta).

https://www.facebook.com/felipe.criadoboado/posts/1748078708651060?hc_ location=ufi (14 de enero de 2019).

Versnel, H. S. 1994. Transition and Revearsal in Myth and Ritual. Leiden: Brill. 